\title{
A projection of BIPV systems in Taiwan: costs versus benefits
}

\author{
K.-J. Hsu \\ Department of Construction Technology, Leader University, Taiwan
}

\begin{abstract}
Because Photovoltaic system tends to save the energy expenditure across the life span of the systems, this paper uses life cycle costing (LCC), saving-toinvestment ratio (SIR), and discounted payback period (DPP) methods to construct the renewable energy evaluation framework in Taiwan. The benefits of PVs mainly derive from energy cost savings, enhanced power quality and reliability, reduced environmental emissions, rebates, and other incentives. Based on the field data of PV-projects located at Taiwan, the paper identifies the technical and economic parameters of the systems evaluation model. The empirical case showed that the saving-to-investment ratio of the BIPV systems with/without government subsidy is not currently feasible in Taiwan. After examining critical factors of the PVs-project, the sensitivity analysis of the future PVs-project was shown. Based on the empirical residential case with a reasonable PR value, the results of sensibility analysis showed that BIPV will become one of the dominant renewable energies in the near future if good, integrated building design is available.
\end{abstract}

Keywords: building-integrated photovoltaic (BIPV), building economics, life cycle costing, saving-to-investment ratio, risk analysis.

\section{Introduction}

Photovoltaic systems (PVs) offer clean, virtually silent and low maintenance power on site. Its potential application depends on the local social-economic development and environmental conditions. It was recently suggested [1-3] that building Integrated Photovoltaic (BIPV) systems consisting of integrated photovoltaic modules into the building envelope could be a cost-effective means of abating $\mathrm{CO}_{2}$ emissions. There has been a dramatic down turn in costs $[1,4,5]$, 
for example, in the 1970s PV modules cost in the region of $£ 15,000 / \mathrm{kWp}$, but in the 1990s costs were down to less than $£ 3,000 / \mathrm{kWp}$ [4].

BIPV systems are increasingly used in building design around the world and have become the symbol and language of innovative, high-tech eco-building. However, one of the major barriers is still the issue of financial feasibility. Hsu et al. [6] used life cycle cost analysis and saving-to-investment ratio to analyze the empirical data of a residential BIPV project located at Kao-Hsiung. The results showed that compared to low electricity cost on the Island, it was still not economically feasible for a home owner/occupant, even with the government subsidy.

Taiwan is not a member of IEA, however, concerning the renewable energy issue, the Bureau of Energy Ministry of Economic Affairs has proposed a subsidized program for those PV system users. More PVs-projects will be promoted in the near future, but in the long run the major barrier is whether a PV-project makes economic sense. This paper looks at the benefit in the reduction of carbon dioxide emissions against the economic evaluation of the BIPV systems. How the key variables will affect the feasibility of the system now and in the future will be discussed.

Instead of focussing on the cost-effective analysis as in previous research, this paper is more concerned with the break-even point of PVs investment. The direct financial benefit of a BIPV system is primarily the energy generated; so in order to examine the effect of discount rate and energy price escalation rate on discounted payback years, the sensitivity analysis was done. On the other hand, because high-humidity climate will affect the efficiency of the PVs in Taiwan, how a ventilated BIPV design will affect the payback years will also be addressed. After examining the performance ratio in Taiwan, the PVs cost down effect and ventilated-BIPV technical improvement will be discussed.

In the following section, the economic evaluation model of the PV system will be developed first. Section 3 introduces the cases that use renewable energy and expounding the economic meaning of the LCC and SIR analysis. Then the sensibility analysis based on DPP method will be extended to discuss the future of PV systems in Taiwan. Finally, the conclusion and discussions were drawn.

\section{The model}

In life cycle cost (LCC) analysis, we need to consider the difference between alternatives when two or more projects are being compared. When evaluating a PVs-project, energy savings need be considered, costs that are common among alternatives that do not affect the selection decision, can be ignored. Assume the discount rates among the discounting periods are known with certainty and invariant, and compare the cost-effectiveness among different kinds of energy alternatives. A comparison between the present values of life cycle cost ( $P V L C C)$ of the renewable energy system to the traditional system determines whether it is cost effective. If the PVLCC is lower than for the traditional base case and in other aspects is equal, and the project meets the investor's objectives and budget constraints, it is considered cost effective and the preferred investment [7-9]. 
On the other hand, because of energy savings and the carbon dioxide $\left(\mathrm{CO}_{2}\right)$, emissions abatement is the major benefit sources of a PVs-project. The present value of a PVs-project can be written as

$$
P W=-C-M\left[\frac{(1+i)^{n}-1}{i(1+i)^{n}}\right]-\sum_{j=5,10,15, . . .}\left[\frac{R P_{j}}{(1+i)^{j}}\right]+R_{0} \sum_{j=1}^{n}\left(\frac{1+e}{1+i}\right)^{j} .
$$

Where PW represents present worth of the cost of the project over the project life of n years; $C$ represents initial cost of the facility. $M\left[\frac{(1+i)^{n}-1}{i(1+i)^{n}}\right]$ represents the present value of the operation and maintenance cost $(P V M)$, and $i$ represents discount rate. $\sum_{j=5,10,15, . . .}\left[\frac{R P_{j}}{(1+i)^{j}}\right]$ represents the present value of the repair or replacement fee $\left(R P_{j}\right)$ at year $j$ of the facilities $(P V R P) . R_{0} \sum_{j=l}^{n}\left(\frac{1+e}{1+i}\right)^{j}$ represents the present value of energy saving respect to year $j$ in the facilities $(P V R)$.

When we evaluate the energy savings of the project, because the price of energy has the characteristic of changing constantly, the energy shortage may cause the violent fluctuation of the price of energy in the future. Considering the rate of energy price escalation trend $(e)$ is always faster than the rate of general price inflation in Taiwan, the present value of energy saving can be evaluated using the following equation [10],

$$
\sum_{j=1}^{n} \frac{R_{j}}{(1+i)^{j}}=\left\{\begin{array}{cc}
R_{0} \frac{\left(f^{n}-1\right) f}{f-1}, & \text { if } f \neq 1 \\
n R_{0}, & \text { if } f=1 .
\end{array}\right.
$$

In which $f=\frac{1+e}{1+i}, R_{j}$ represents the net cash inflow from energy saving at year $j$, and $R_{0}$ is the energy saving benefit respect to initial energy price. For example, if the annual output of the PVs-project is $E$, and the initial unit price of the traditional power is $P_{0}$, the annual energy savings at initial time are $R_{0}=E P_{0}$. Because $P V M, P V R P$ are only a small part of the PVLCC, the payback year of the project can be simplified as follows:

$$
P P_{D C F}=\frac{\ln \left[1+\left(\frac{C+P V M+P V R P}{R_{0}}\right)(f-1)\right]}{\ln f} .
$$


Discounted payback period (DPP) method calculates the time point at which accumulated savings net of the accumulated cost is sufficient to offset the initial costs. The payback year method is essentially a break-even measure which can be used to determine the minimum time a BIPV system must last to recover the investment costs. The DPP is often used as a rough guide to cost-effectiveness. Extending the results to the future prospect discussion, the sensitivity analysis of the DPP is quite a suitable tool.

\section{The critical factors of economic feasible for PV systems}

The parameters of a PVs-project feasibility analysis include: the financial parameters (discount rate, price escalation rate), and the technical parameters of PVs (the life span of PVs, timing of component replacement, cost of initial cost, etc.). Treating PVs as consumable goods for the household, the opportunity cost of the consumable goods can be estimated as the average fixed deposit rate of Taiwan. Considering the financing behaviour characteristic of the general family in Taiwan, in this paper we set the discount rate as 3\%. The financial parameters in this paper mostly refer to statistical data from the Directorate General of Budget, Accounting and Statistics, Taiwan. The technical parameters mostly refer to datasheets from the respective manufacturer, for example, the life of the $\mathrm{PV}$ panel is assumed as 20 years.

The results show that the present value of the opportunity cost larger than the present value of the energy savings from systems. The net present value of the system is negative. Without the government subsidy, the SIR of the residential off-grid case located at Kao-Hsiung is about $13.7 \%$ and with the government subsidy about $21.9 \%$. In case of grid-connected industrial facility located at Taichung the SIR upgrade to $16.6 \%$ in respect to the case without subsidy, and $26.8 \%$ in respect to the case with subsidy. Low energy saving benefit and high technological cost are the major reasons that result in the PV systems not being economically feasible in Taiwan now.

The PVs-project output is affected by the solar radiation amount available on the site and the performance ratio (PR) of the systems. Given an average PR value evaluated at yearly basis and the local solar radiation available at the site (dimensionless), the annual output (kWh) of the PVs project can be calculated as follows:

$$
E=P R \bullet Y_{r} \bullet W .
$$

Let the reference yield equal to total in-plane irradiance divided by the PV's reference irradiance ( $Y_{r}=H / G$, hour); $W$ represents the nameplate d.c. power of the installed PVs $(\mathrm{kW})$. If $\mathrm{G}$ equals $1 \mathrm{kWh} / \mathrm{m}^{2}$, then $Y_{r}$ is the number of peak sun-hours, it represents an equivalent number of hours at the reference irradiance. By normalizing with respect to irradiance, PR value quantifies the overall effect of losses on the rated output. Because of losses due to PV module temperature, PR values are greater in the winter than in the summer [11]. 
In the following subsections, the key factors examined are (a) solar radiation, (b) PR, (c) thermal and ventilated-BIPV design issues, (d) energy price and its escalation trend which affect savings of the systems.

\subsection{Solar radiation in hot-humidity region}

The level of solar resource has an impact on the output of a PVs-project. Taiwan located at low latitude about $23^{\circ} \mathrm{N}$, is hot-humidity region with slight differences of temperature and slight changes of solar radiation in the four seasons. However, unstable climate such as cloud and rain in the spring and typhoons in the summer, lower the annual solar radiation. Compared to bell shape solar radiation across the year in low-high latitude region, the daily radiation across the year of Taiwan has only a slight change.

Table 1 shows that the variation of annual solar radiation across the island ranges from 801 to $1560 \mathrm{Wh} / \mathrm{m}^{2} /$ year, and the average is lower than $48^{\circ} 00^{\prime} \mathrm{N}$ at the Freiburg. Figure 1 shows the daily output of "stand-alone type" BIPV systems in Southern Taiwan, it seems there is little significant difference across the whole year. Most PVs research papers concluded that sites closer to the equator have higher solar resources [2, 12]. However, Taiwan is an unusual case, as the micro-climate patterns affect the PVs output to a greater degree.

Table 1: $\quad$ Annual radiation comparison across different latitude $[12,13]$.

\begin{tabular}{|l|r|r|}
\hline & Latitude & Annual solar radiation $\left(\mathrm{Wh} / \mathrm{m}^{2} /\right.$ year $)$ \\
\hline Taiwan-1 (Max) & & 1,560 \\
\hline Taiwan-2 (Average) & $\pm 23^{\circ} \mathrm{N}$ & 1,059 \\
\hline Taiwan-3 (Min) & & 801 \\
\hline Sahara & $25^{\circ} 00^{\prime} \mathrm{N}$ & 2,500 \\
\hline Israel & $33^{\circ} 00^{\prime} \mathrm{N}$ & 2,000 \\
\hline Los Angles, USA & $34^{\circ} 30^{\prime} \mathrm{N}$ & 1,816 \\
\hline Athens, G & $37^{\circ} 58^{\prime} \mathrm{N}$ & 1,580 \\
\hline Trapani, I & $38^{\circ} 00^{\prime} \mathrm{N}$ & 1,800 \\
\hline New York, USA & $40^{\circ} 47^{\prime} \mathrm{N}$ & 1,424 \\
\hline Rome, I & $41^{\circ} 48^{\prime} \mathrm{N}$ & 1,529 \\
\hline Toronto, C & $43^{\circ} 40^{\prime} \mathrm{N}$ & 1,380 \\
\hline Freiburg, D & $48^{\circ} 00^{\prime} \mathrm{N}$ & 1,100 \\
\hline London, UK & $51^{\circ} 29^{\prime} \mathrm{N}$ & 898 \\
\hline Berlin, G & $52^{\circ} 28^{\prime} \mathrm{N}$ & 1,026 \\
\hline Helsinki, FIN & $60^{\circ} 00^{\prime} \mathrm{N}$ & 950 \\
\hline Lerwick, UK & $60^{\circ} 00^{\prime} \mathrm{N}$ & 775 \\
\hline
\end{tabular}




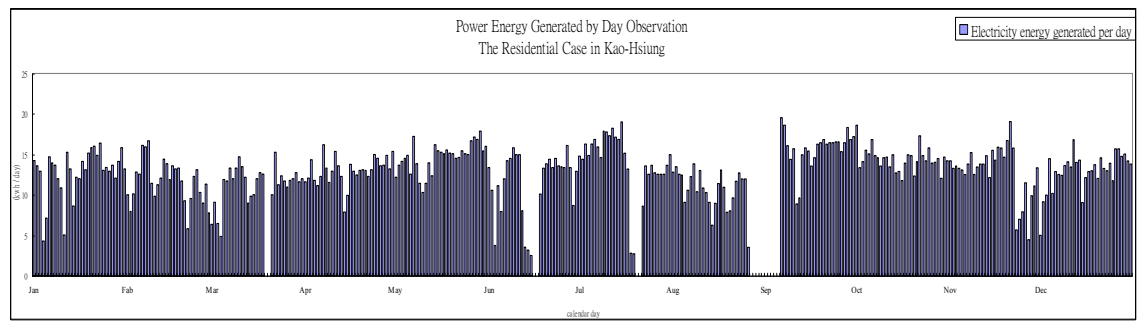

Figure 1: Daily power output across year of the residential off-grid BIPVproject located at Kao-Hsiung.

\subsection{Performance ratio}

The productivity of PVs-project relative to the solar radiation it receives is measured by the PR value, although there are some special grid-connected cases demonstrated by government showing that PR value is greater than $80 \%$. In the empirical case of "stand-alone type PVs-project", system output will be shut-off after the battery is fully charged. According to field data of the cases study here, the residential roofing PVs showed that the PR value $53.2 \%$, is lower than the grid-connected case of a Taichung Industrial facility $65.5 \%$.

The low PR value in the residential case located at Kao-Hsiung can be traced to the use of a stand-alone system. This is because main electricity systems do not provide incentive and good connected network support for individual small micro-generations. Taiwan is a country at the earliest stage of starting to use PVs. Most PVs PR values in Taiwan are lower than in London, New York, Los Angeles and Germany, where the average PR is $70 \%[2,11,13]$.

\subsection{Thermal issue and ventilated-BIPV}

As BIPV modules are installed on building envelope, obviously the changes of exterior environment or climatic conditions will affect their total performance, hot-humidity climate in Taiwan results in high temperature, and low PR value. Among a variety of factors, heat has a direct influence on PV. If the temperature of $\mathrm{PV}$ is above $25^{\circ} \mathrm{C}$, the effect of temperature arise on solar cell efficiency is negative and material dependent. For example, the efficiency of crystalline solar cells falls whenever the temperature increases, the decrease in the rate of the efficiency is estimated at about $0.4 \%$, which is lower than the rate under STC [12]. In contrast, the behaviour with diffused light, increased temperature, and shading for amorphous showed a high energy yield in $\mathrm{kWh}$ per $\mathrm{kW}_{\mathrm{p}}$ and thus a high performance ratio.

An experiment of ventilated BIPV using CFD simulation showed that compared to traditional BIPV design, a ventilated BIPV saves about $8-26 \%$ of energy consumption. Also a ventilated BIPV can provide low solar cell temperature and good performance for PV systems. In order to ensure the nominal PV efficiency, the choice of solar cell material and appropriate 
ventilation are therefore necessary. In other words, the application of PVs installed in buildings must pay attention to ventilation and thermal issues, so as to have a better energy savings and to maintain a high PR value.

\subsection{The benefits from energy savings and price escalation rate}

The benefits of renewable energy are mainly derived from the saving of traditional energy and clean energy environment benefits. With LCC, we learn that the benefits of renewable energy rely on the pricing model of traditional energy. To boost their economies, developing countries tend to lower the cost of traditional energy to supply low-priced energy to industries. In Taiwan, the power supply is controlled by a company owned by the MOEA, a governmentowned company. The price of energy tends to be low for overall economic development. The price does not reflect the real economic cost. This results in the benefits from the renewable energy project being relatively low.

The data shows that the past upward rate of the price of electricity lie between 1 to $2 \%$ in Taiwan, and the upward rate of the price of electricity is estimated by government to be about $2 \%$ per year. Because LCC is considered with the whole life cycle, in a situation that the petrochemical energy is limited, the relevant price of electricity, coal and gas certainly will be going up constantly in the future. Combining the price escalation rate of the electricity energy and using the observation of electricity energy generated in the first year as the estimation of the following lifetime energy savings, the illustrative example in the following section will analyze the sensitivity of DPP change with respect to energy price escalation rate change.

\section{Sensitivity analysis}

According to the results of LCC and SIR analysis, it is not economically feasible for a home owner-occupant of PVs in Taiwan. The result also shows that it cannot break-even in the life span of the system. The discounted payback years are larger than the life of the system. The reasons include thermal issue of BIPV design in the hot and humid climate region, energy cost and price policy, sell-back-price of the renewable energy, higher technology cost and lower electricity generation of PVs.

Comparing the results and economy of PVs to those of developed countries, the PVs cost in Taiwan is relatively high. On the other hand, the energy savings from PVs output in Taiwan is relatively low compared with Japan and EU countries. Considering the cost down trend of PVs and PV industry developed recently in the Island, the data used now represents the developing technologies of PVs rapidly becomes obsolete. The effects of cost trend have been analyzed in many papers $[1-5]$.

The reason for low energy price include the land pipeline cost is lower for Tai-Power Company, and environmental cost is almost ignored. Therefore, TaiPower has lower cost of power generation, which leads to lower power saving economic benefits. But in the progresses of economic and environmental 
development, the energy price policy has been keenly discussed. The high price energy and high escalation rate will be the critical issue the Island needs to face.

Critical parameters that influence the assessment result include low energy savings, cost down trend, study period, and discount rate etc. To meet the economic sense, the paper uses equation (3) and based case of the future prospect to analyze the sensitivity of energy price escalation rate and discount rate on DPP without subsidy. The base case conditions of the sensitivity analysis include EU documents showing that PV cost will be anticipated to decrease by half in 2010-2015; and based on the empirical residential case analysis located at KaoHsiung, by which enhanced PR value to $70 \%$, an average level of a developed country.

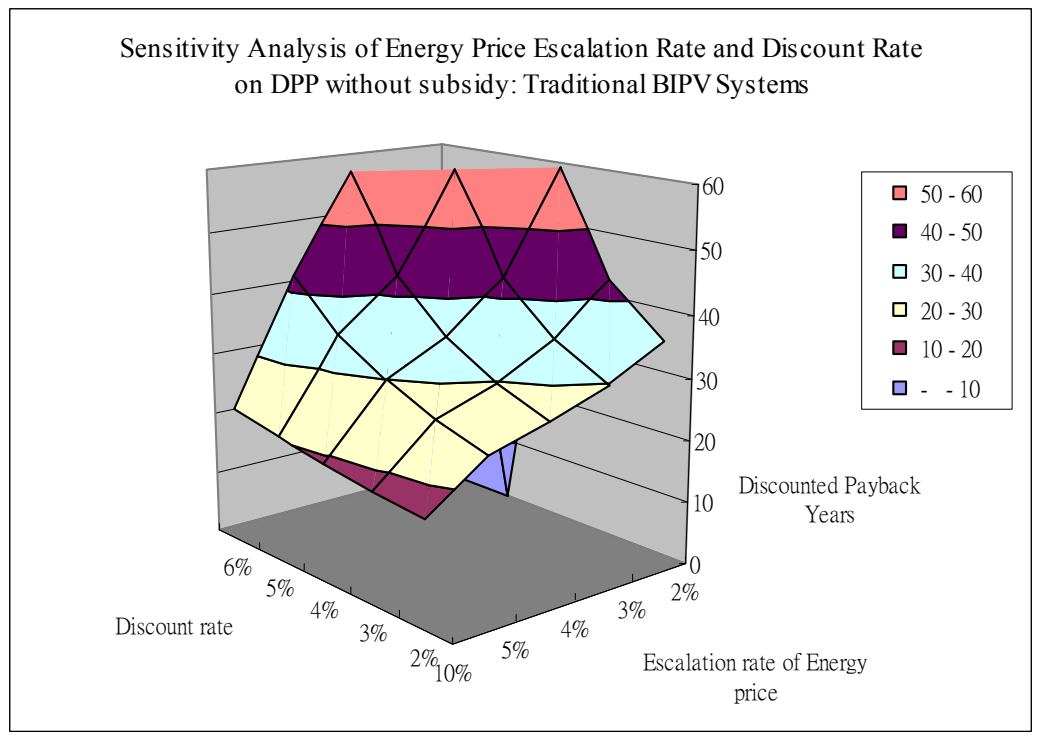

Figure 2: $\quad$ Sensitivity analysis of energy price escalation rate and discount rate on DPP without subsidy: traditional BIPV systems.

Fig. 2 shows the results of sensibility analysis for traditional BIPV respect to energy price escalation rate and discount rate on DPP. The Figure shows that with higher escalation rate of electricity price and lower discount rate, discounted payback years of BIPV systems will be less than 20 years. For example, when escalation rate of electricity price is $8 \%$ (this is most likely the energy market rate now) and discount rate is $3 \%$, the DPP of the BIPV project will be down to 20 years. Higher escalation rate of electricity price will lower the DPP. Adopting ventilated-BIPV will lower the DPP threshold more.

Fig. 3 shows the simulation results in the case of ventilated-BIPV. The Figure shows that Ventilated BIPV can achieve shorter payback years. When escalation rate of electricity price is $8 \%$ and discount rate is $3 \%$, the DPP of the BIPV project is down to 18 years. This should be feasible in a real case, and is thus 
good for an architect making energy-saving designs. Under such a case, BIPV will become one of the dominant renewable energies in the near future if integrating good building design is available. It is worth studying further and exploring the potentials in advance.

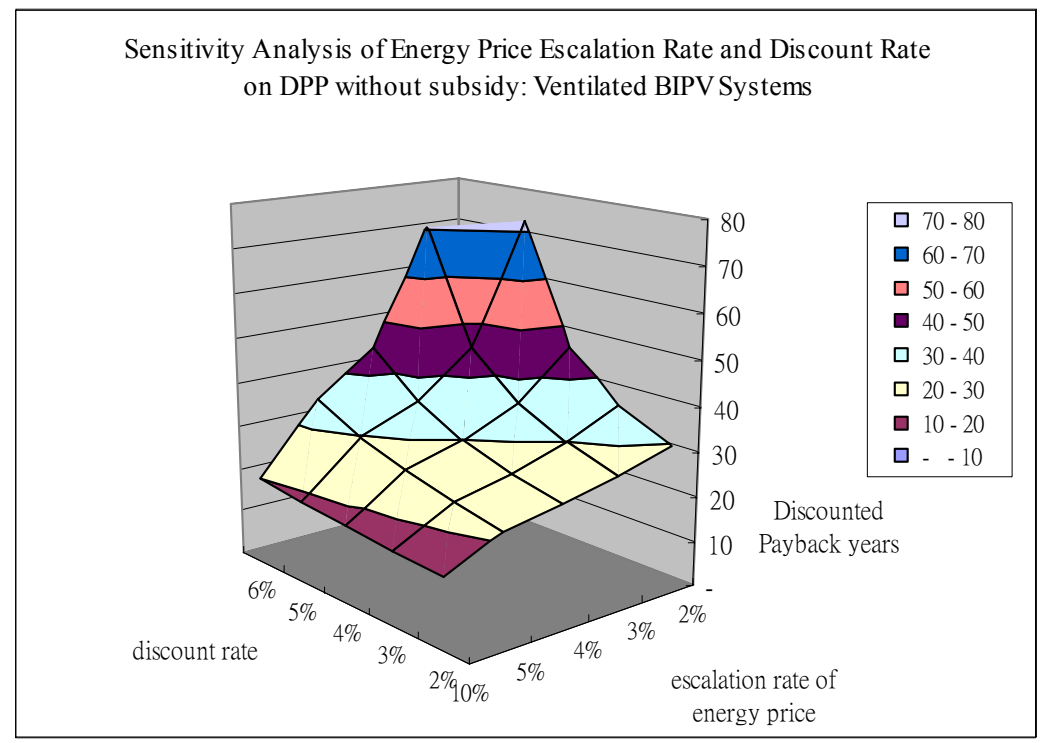

Figure 3: $\quad$ Sensitivity analysis of energy price escalation rate and discount rate on DPP without subsidy: Ventilated BIPV systems.

\section{Conclusion}

The benefits of BIPV system mainly derive from energy cost savings, enhanced power quality and reliability, reduced environmental emissions, rebates, and other incentives. The paper uses the empirical data and the economic evaluation model to explore the future of BIPV development in Taiwan. After examining critical factors after the PVs-project, the sensitivity analysis of the future PVsproject was shown. Based on the empirical residential case analysis located at Kao-Hsiung with a reasonable PR value, the results of sensibility analysis showed that BIPV will become one of the dominant renewable energies in the near future if integrating good building design is available. With higher escalation rate of electricity prices and lower discount rates, discounted payback years of BIPV systems will be less than 20 years. Adopting ventilated-BIPV will lower down the DPP threshold even more.

\section{Acknowledgement}

Support from the National Science Council of ROC through grant NSC 96-2221E-426-008 in this study is gratefully acknowledged. 


\section{References}

[1] Oliver, M. and Jackson, T. The market for solar photovoltaics. Energy Policy 27, 371-385, 1999.

[2] Oliver, M. and Jackson, T. The evolution of economic and environmental costs for crystalline silicon PVs. Energy Policy 28 (14): 1011-1021, 2000.

[3] Oliver, M. and Jackson, T. Energy and economic evaluation of buildingintegrated photovoltaics. Energy 26 (4): 431-439, 2001.

[4] Lesourd, J-B. Solar photovoltaic systems: the economics of a renewable energy resource. Environmental Modelling \& Software 16 (2): 47-156, 2001.

[5] Maycock, P. Cost reduction in PV manufacturing. Impact on gridconnected and building-integrated markets. Solar Energy Materials and Solar Cells 47, 37-45, 1997.

[6] Hsu, K-J, Lai, C-M and Chiang, C-M. The Economic Evaluation of Building-integrated Photovoltaic Systems. Proceedings, Annual Conference - Canadian Society for Civil Engineering, v 1, Annual Conference of the Canadian Society for Civil Engineering 2007: Where the Road Ends, Ingenuity Begins, pp. 390-397, 2007.

[7] ASTM, Standard Practice for Measuring Life-Cycle of Buildings and Building Systems. Annual Book of ASTM Standards, Vol. 04.11, January 1995, America.

[8] Eiffert, P. Guidelines for the Economic Evaluation of Building-Integrated Photovoltaic Power Systems. Technical Report, NREL/TP-550-31977, National Renewable Energy Laboratory, 2003.

[9] Ruegg, R.T. and Marshael, H.E. Building Economics: Theory and Practice. New York: Van Nostrand Reinhold, 1990.

[10] Terpenny, J.P., Ambs, L.L., Dixon, J.R., Sullivan, J.L. and Sullivan, W.G. The Engineering Economics of Energy Use and Capital Investment. Proceedings of the 2003 ASEE Annual Conference, 2003.

[11] B. Marion, B., Adelstein, J., Boyle, K., Hayden, H., Hammond, B., Fletcher, T., Canada, B., Narang, D., Shugar, D., Wenger, H., Kimber, A., Mitchell, L., Rich, G and Townsend, T. Performance Parameters for GridConnected PV Systems. 31st IEEE Photovoltaics Specialists Conference and Exhibition, 2005.

[12] The German Solar Energy Society (DGS), Planning and Installing Photovoltaic Systems: A guide for installers, architects and engineers, James \& James Science Publishers Ltd. UK: London, 2005.

[13] International Energy Agency, Photovoltaics in Buildings: A Design Handbook for Architects and Engineers, James \& James Science Publishers Ltd, 1998. 